\section{Assaults on psychiatrists}

Sir-O'Sullivan and Meagher ${ }^{1}$ presented an interesting study of this important subject. They were, however, unable to find any significant factors which put psychiatrists at risk of patient-perpetrated violence. They quote a review article of mine ${ }^{2}$ which contains an unfortunate misprint - 'decrease' instead of 'increase', although the true message is suggested thereafter: 'ie. there is a significantly higher risk of novices being attacked than veterans'. This deduction is based on a study published in the medical press ${ }^{3}$ (ref. 40 in the review paper) wherein Tables 3 and 4 show that the bulk of assaults are concentrated in the earlier parts of a psychiatrist's career as evidenced by the lack of an increase in reported number of assaults as experience lengthens. In my study the mean number of years in psychiatric practice was 18.56 years, range 6-34 years, with a total of 1,225 years. The mean for the O'Sullivan and Meagher study was 7.2 years, range one month to 38 years.

O'Sullivan and Meagher divided their sample into 10 year age groups, finding some protective effect in the 45 54 year old group, whereas I divided up my sample on the basis of years of exposure to risk, ie. years practicing psychiatry. It would have been interesting to see what effect the latter methodology might have has on the results of the former study.

Brian O'Shea FRCPsych, Consultant Psychiatrist, Newcastle Hospital, Greystones, Co Wicklow, Ireland.

\section{References}

1. O'Sullivan M, Meagher D. Assaults on psychiatrists - a three year retrospective study. Ir I Psych Med 1998; 15(2): 54-7.

2. O'Shea B. The violent breed: a review of human violence, with particular attention $\mathbf{t o}$ that perpetrated by patients against doctors. Ir J Psych Med 1988; $5(1): 6-10$.

3. O'Shea B. Attacks on psychiatrists. Ir Med News 1987:3(32): 10.

\section{RE: Hypertension and increased serum clozapine associated with clozapine and fluoxetine in combination}

Sir - In their case report Sloan and O'Boyle ${ }^{1}$ suggest that the elevation of serum clozapine and norclozapine with the combination of clozapine and fluoxetine is through the inhibition of the cytochrome P450 CYP2D6 isozyme, and that due consideration should be given to the genetic variation of this enzyme in clinical practice. Although an in vitro study ${ }^{2}$ has demonstrated that clozapine is metabolised by CYP2D6, subsequent findings have demonstrated that there is a lack of association between clozapine metabolism and debrisoquine and S-mephenytoin hydroxylation polymorphism, ${ }^{3}$ and that the CYP2D6 genotype does not affect clozapine clearance. ${ }^{4}$ These studies suggest that CYP2D6 may not be involved in metabolism of clozapine in vivo. We would like to propose that the more likely mechanism underlying the increased serum clozapine levels is mediated by the altered activity of CYP3A4. This enzyme which is involved in the metab- olism of clozapine, is also inhibited by fluoxetine and thus would lead to elevation of clozapine concentrations ${ }^{5}$ when these two drugs are prescribed concomitantly.

\section{Siow-Ann Chong, MBBS, MMed(Psych) Fellow, \\ Gary Remington, MD, PhD, FRCP(C) Director, Medication Assessment Programme, Schizophrenia Division, Clarke Institute of Psychiatry, Toronto, Ontario, Canada.}

\section{References}

1. Sloan D, O'Boyle J. Hypertension and increased serum clozapine associated with clozapine and fluoxetine in combination. Ir J Psych Med 1997; 14:151-2. 2. Fisher V, Vogels B, Maurer G, Tynes R. The antipsychotie clozapine is metabolised by the polymorphic human microsomal and recombinant cytochrome P450 2D6. J Pharmacol Exp Ther 1992; 260: 1355-60.

3. Dahl M, Llerena A, Bondesson U et al. Disposition of clozapine in man: lack Dahl $M$ illerena $A$, Bos polymorphism. Br J Clin Pharmacol 1994; 37: 71-4

4. De Leon J, Wedlund P, Ehlers R et al. Cytochrome P450 2D6 (CYP2D6 genotype: relationship with clozapine and haloperidol metabolism. Biol Psychiatry 1996; 39: 591.

5. Glue P, Banfield C. Psychiatry, psychopharmacology and P-450s. Human Psychopharmacology 1996; 11:97-114

\section{RE: Clozapine-fluoxetine and the CYP450 system}

Sir - We thank Chong and Remington for their letter and interesting comments, and would like to add that there is still controversy in the literature over which of the various subtypes of cytochrome $\mathrm{P} 450$ are responsible for the metabolism of clozapine.' CYP1A2, CYP2D6 and CYP3A4 have all been found to be involved in the metabolism clozapine, and much of the evidence points toward CYP1A2 as being the most important. ${ }^{1-3}$ CYP3A4 is not the major isoenzyme involved in the metabolism of clozapine, and while fluoxotene and its metabolite norfluoxetine have been shown to inhibit CYP3A4 this effect is minimal. ${ }^{4}$ It is certainly possible that inhibition of this isoenzyme may have contributed to the raised clozapine and norclozapine levels, in our patient, and we accept the cited evidence indicating that CYP2D6 genotype does not effect clozapine clearance. ${ }^{5}$ It is possible however that inhibition of the CYP2D6 system also contributed to the raised clozapine and norclozapine levels by the inhibition of a metabolic step distal to clozapine N-dealkylation ie. inhibition of secondary resulting in raised plasma levels of clozapine and norclozapine, but no change in the plasma clozapine/norclozapine ratio.' Furthermore the antidepressant medication nefazodone, which is a known CYP3A4 inhibitor has been shown to have no effect on clozapine metabolism. ${ }^{6}$ Thus further clarification of the role of the different cytochromes involved in the metabolism of clozapine is warranted, and we would still advocate caution when coadministering drugs which have proven inhibitory action on the cytochrome P450 isoenzyme.

Darina Sloan, MB, MRCPsych, Senior Registrar in psychiatry, University College Hospital, Galway, Ireland.

James O'Boyle MB, FRCPsych, Consultant Psychiatrist, St Vincent's Hospital, Fairview, 
Dublin 3, Ireland.

References

1. Taylor D. Pharmacokinetic interactions involving clozapine. Br J Psychiatry 1997; 171: 109-12.

2. Jerling M, Lindstrom L, Bondesson $U$ et al. Fluvoxamine inhibition and carbamazepine induction of the metabolism of clozapine: evidence from a therapeutic drug monitoring service. Ther Drug Monit 1994; 16(4): 368-74. 3. Pirmohamed M, Williams D, Madden S et al Metabolism and bioactivation of elozapine by human liver in virro. J Pharmacol Exp Ther 1995 Mar; 272(3): $984-90$.

4. Von Moltke LL, Greenblatt DJ, Cotreau-Bibbo MM et al. Inhibitors of alprzolam metabolism in vitro: effect of serotonin-reuptake inhibitor antidepressants, ketoconazole and quinidine. Br J Clin Pharmacol 1994; 36 $615-6$

5. Dahl M, Llerena A, Bondesson U et al. Disposition of clozapine in man: lack of association with debrisoquine and $S$-mephenytoin hydroxylation of association with debrisoquine and $S$-mephen

6. Taylor D (Chief Pharmacist) Bethlem and Maudsley NHS Trust, Honary Lecturer, Institute of Psychiatry (personal communication).

\section{RE: False Memory Syndrome - Balancing the evidence for and against}

Sir - Following publication of this paper, I have been asked whether I would care to comment further in the light of the recent Brandon Report, which has been published since my paper was accepted. (Brandon et al 1998)

Most of the conclusions and recommendations of the Brandon Report will be endorsed by the psychiatric profession. Both the report and my paper emphasise that we have a responsibility not to cause harm to patients or their families.

The Report makes the following statements:

"There can be no justification for the use of memory recovery techniques which involve significant departure from normal interview or psychotherapy techniques".

It adds, "Great caution is needed if memory is reported after years of apparent amnesia. There is considerable evidence that such memories cannot be relied upon". It goes on to make extremely helpful recommendations regarding interview procedures.

Both the Brandon Report and my own paper emphasise that if accounts of sexual abuse in childhood are to be believed, then there must be corroborative evidence. It is deplorable that so many families have been harmed by the 'discovery' of previous sexual abuse, when no such abuse has occurred.

The difference in view point between the Brandon Report and my paper is this. The Report states, "given the prevalence of childhood sexual abuse, even if only a small proportion are repressed and only some of them are subsequently recovered, there should be a significant number of corroborated cases. In fact there is none".

I quoted one or two cases at length in my paper. This was to emphasise that even if there are only one or two well documented cases, this would prove that sexual abuse may indeed occur, be forgotten, and subsequently be recalled. It is my opinion that this happens although probably rarely.

Extreme caution needs to be exercised before any accounts of sexual abuse which are 'remembered during therapy' are believed, and definite corroborative evidence should always be obtained where possible. It will be interesting to see if further well documented cases come to light.

Stephen Critchlow, MRCPsych,
Specialist Registrar in Psychiatry, Down Lisburn Trust, Downshire Hospital, Ardglass Rd, Downpatrick, Co Down BT30 6RA, Northern Ireland.

\section{References}

1. Brandon S, Boakes J, Glaser D et al. Recovered memories of childhood sexual abuse. Implications for clinical practice. Brit J Psychiatry 1998; 172: 296-307. 2 . Critchlow S. False Memory Syndrome - balancing the evidence for and against. Ir J Psych Med 1998; 15(2): 64-7.

\section{False Memory Syndrome}

Sir-Dr Critchlow is to be congratulated on his effort to balance the evidence in this difficult area (IJPM June 1998). It is an issue that will continue to be debated for many years. The most important fact for psychiatrists to grasp is that false memories of childhood abuse can be induced and often the results cause great suffering in families and in the 'victim'. There are some techniques which are particularly likely to result in false memories, most of them discredited techniques and these will be avoided by sensible doctors. ${ }^{.}$What is not always recognised is that in any therapeutic relationship the therapist may inadvertently communicate his/her beliefs and expectations to the subject. Public and professional education can bring about dramatic changes. The so called epidemic of recovered or false memories seems to have come to an end in the USA though whether this is due to the successful litigation against therapists or widespread professional and media attention remains uncertain. ${ }^{2}$ We have a clear duty to avoid the creation of false memories but we must also treat with respect and concern anyone who presents with a story of childhood abuse. Where these are memories recovered after a long period of amnesia then an element of scepticism is justified but psychotherapy rather than confrontation is then called for.

Sydney Brandon, MD, FRCP, FRCPsych, DPM, DCH, 19 Holmfield Road, Leicester LE2 1SD, England.

\section{Fatal pharmacokinetic interaction involving amitriptyline combined with valproate and clozapine}

Sir - The purpose of this case history is to draw attention to the possible fatal consequences of combining amitriptyline with valproate and clozapine.

A physically healthy young adult male was diagnosed as suffering from schizophrenia in 1993. This was complicated at times by a significantly depressed affect which required antidepressant medication.

Following failure to respond to standard antipsychotic medication he was commenced on clozapine, with some clinical improvement. However he experienced epileptiform-like phenomena which were confirmed by an EEG. Consequently the dose of clozapine was reduced to $200 \mathrm{mg}$ bd and prophylactically he was commenced on valproate $500 \mathrm{mg}$ bd, which appeared to successfully alleviate this side-effect. During this time he continued to receive 